\title{
Demographic Risk Factors, Affected Anatomical Sites and Clinicopathological Profile for Oral Squamous Cell Carcinoma in a North Indian Population
}

\author{
Akhilesh Krishna ${ }^{1}$, RK Singh², Shraddha Singh*, Pratima Verma1, US Pal², \\ Sunita Tiwari ${ }^{1}$
}

\begin{abstract}
Background: Oral cancer is a common form of cancer in India, particularly among men. About $95 \%$ are squamous cell carcinomas. Tobacco along with alcohol are regarded as the major risk factors. Objectives: (i) To determine associations of oral squamous cell carcinoma (OSCC) with respect to gender, age group, socioeconomic status and risk habits; (ii) To observe the distribution of affected oral anatomical sites and clinico-pathological profile in OSCC patients. Materials and Methods: This is an unmatched case-control study during period January 2012 to December 2013. Total of 471 confirmed OSCC patients and 556 control subjects were enrolled. Data on socio-demography, risk habits with duration and medical history were recorded. Results: There were significant associations between OSCC with middle age (41-50years; unadjusted $\mathrm{OR}=1.63,95 \% \mathrm{CI}=1.05-2.52$, $\mathrm{p}=0.02)(51-60$ years; unadjusted $\mathrm{OR}=1.79,95 \% \mathrm{CI}=1.15-2.79, \mathrm{p}=0.009)$ and male subjects (unadjusted $\mathrm{OR}=2.49$, 95\% $\mathrm{CI}=1.89-3.27, \mathrm{p}=\mathbf{0 . 0 0 0 1}$ ). Cases with both habits of tobacco chewing and smoking were at a higher risk for OSCC than tobacco chewing alone (unadjusted $\mathrm{OR}=0.52,95 \% \mathrm{CI}=\mathbf{0 . 3 8 - 0 . 7 2}, \mathrm{p}=\mathbf{0 . 0 0 0 1}$ ), duration of risk habits also emerged as a responsible factor for the development of carcinoma. The majority of patients were presented in well-differentiated carcinomas (39.9\%). Prevalence of advance stages (TNM stage III, IV) was $23.4 \%$ and $18.3 \%$ respectively. The buccal mucosa was the most common (35.5\%) affected oral site. Conclusions: In most Asian countries, especially India, there is an important need to initiate the national level public awareness programs to control and prevent oral cancer by screening for early diagnosis and support a tobacco free environment.
\end{abstract}

Keywords: Oral squamous cell carcinoma - smokeless tobacco - risk habits - histopathology

Asian Pac J Cancer Prev, 15 (16), 6755-6760

\section{Introduction}

In the present scenario world is heading towards various types of non-communicable diseases, among these cancer is one of the most common causes of morbidity and mortality (A Mathur et al., 2007). Worldwide, approx >10 million new cases and $>6$ million deaths occur each year due to cancer and oral cancer is estimated to be the sixth most common cancer. (WHO, 2004; Warnakulasuriya, 2009). It is estimated that approximately 2 to 2.5 million cases of cancer at any given point of time, with around 7 to 9 lakhs new cases being detected each year in India (Government of India, 2009-2010). National Cancer Registry Programme of Indian Council of Medical Research reported highest number of oral cancers worldwide with up to 80,000 new cases annually (ICMRNCRP, 2011).

Despite several diagnostic and therapeutic advances, the overall incidence and mortality associated with oral cancer is rising in India, with current estimate of age- standardized incidence and mortality being 6.6 per one lakh and 3.1 per one lakh population for males and 2.9 per one lakh and 1.4 per one lakh in females respectively (Carvalho et al., 2004). The oral squamous cell carcinoma (OSCC) represents more than $90 \%$ of malignant neoplasms of the mouth (Bagan et al., 2010). The principal anatomic zones of OSCC are the tongue, floor of the mouth, gums, palate, oral mucosa, and other sites in the mouth. The anatomic zones or sites affected vary based on geographical areas (Hernandez et al., 2013). Consumption of alcohol, tobacco smoking, unhealthy diets, sedentary lifestyles, and viral infections are risk factors for cancer development. Drinking alcohol and smoking tobacco can synergistically cause cancer of the oral cavity, pharynx, larynx, and esophagus (Petti and Scully, 2005; Warnakulasuriya et al., 2005). The International Agency for Research on Cancer has confirmed that use of smokeless tobacco causes oral cancer (Cogliano et al., 2004). Global Adult Tobacco Survey (GATS) data from Indian states and union territories conducted during 2009- 
2010, has reported approximately 274.9 million tobacco users in India. As per this report more than one-third (35\%) of adults use tobacco in some form or the other, 163.7 million are users of only smokeless tobacco, 68.9 million only smokers, and 42.3 million users of both smoking and smokeless tobacco (Ministry of Health and Family Welfare, India, 2010).

Incidence and survival rates of cancer are clearly linked to socioeconomic factors, low-income and disadvantaged groups. Low socio-economic status is as well significantly associated with increased oral cancer risk in high and lower income-countries, across the world (Conway et al., 2008).

Though many epidemiological studies about oral cancer have been done in the different parts of India but only few studies were carried out in reference to association of demographical risk factors and clinicopathological profile for OSSC in the north region of India. Hence, objectives are $i$ ) To determine the association of OSCC with respect to gender, age group, socio-economic status and risk habits $i$ ) To observe the distribution of affected oral anatomical sites and clinico-pathological profile in OSCC patients.

\section{Materials and Methods}

This is an unmatched case-control study, conducted in the Department of Oral and Maxillofacial Surgery, King George's Medical University, U.P., Lucknow, India for a period of 2 years (January 2012 to December 2013). The present study included medical history, age, gender, risk habits with duration (tobacco and alcohol consumption) of subject.471 clinically and histopathologically confirmed OSCC patients with cancer of buccal mucosa, alveolus, tongue, gingo-buccal cavity, palate, retromolar trigone and floor of mouth were included in case group(excluding those with salivary gland and lip tumors) and 556 subjects were included in control group with no chronic illness, no history of head and neck surgery and non-cancer conditions. Data for cases was collected from questionnaire, case history sheet of patient and oral mucosal biopsy report. However, information regarding control group subjects was collected by general questionnaire, history sheet after obtaining their informed consent.

The subjects were categorized in to age groups and socio-economic classes; according modified Kuppuswamy's socio-economic scale (Mishra and Singh; 2003). In Histopathological investigations, tumor was graded according to degree of differentiation and keratinization of tumor cells; Grade I- Well-differentiated tumors, Grade II- Moderately differentiated tumors, Grade III- Poorly differentiated tumors, Grade IV- Anaplastic tumor. Clinical diagnosis of OSCC patients was carried out according to the TNM classification of the American Joint Committee for cancer staging (Doshi et al., 2011).

Risk habits of the both case and control group subjects, chewers and smokers were defined as those chewing smokeless tobacco and its product such as betel quid (paan) with tobacco mixing, gutkha, paan masala, zarda, khaini etc. with or without combination of tobacco smoking like cigarette , beedi at least one time per day for a period of one year continuously. Alcohol drinking was defined as intake of any type of alcohol at least once a month for one year continuously with or without combination of tobacco chewing or smoking. So all the subjects were distributed according their personal habit(s) -without any adverse habits (no habit), only Smokeless tobacco chewing (SLT), tobacco smoking (TS), both tobacco chewing and smoking (SLT+TS) and alcoholic with or without use of tobacco in any form (Alcohol \pm SLT \pm TS). Duration (in years) was recorded for any type of risk habit. This study has been approved by Institutional Ethics Committee, King George's Medical University, U.P., Lucknow, India.

\section{Statistics}

Analysis was carried out by using SPSS 16.0 version and the results are presented in percentages. The univariate and multivariate logistic regression analysis was carried out to identify the risk of OSCC in both cases and controls. The unadjusted and adjusted odds ratios (OR) were calculated with its $95 \%$ confidence intervals (CI). The p-value $<0.05$ was considered significant.

\section{Results}

A total 471 cases of histopathologicaly verified OSCC were reported during study period while 556 subjects were recruited for control group in this study. The demographic characteristics and risk habits of both case and control subjects are summarized in Table 1. Most of OSCC patients were in the age group of 41-50 years (25.7\%). The risk of OSCC was 1.79 and 1.63 times significantly higher among the age group of 51-60 (Unadjusted $\mathrm{OR}=1.79,95 \% \mathrm{CI}=1.15-2.79, \mathrm{p}=0.009)$ and $41-50$ years (Unadjusted $\mathrm{OR}=1.63,95 \% \mathrm{CI}=1.05-2.52, \mathrm{p}=0.02$ ) respectively than age group of $\leq 30$ years. Prevalence of males in OSCC cases was $77.9 \%$ and at significantly higher risk of OSCC than females (Unadjusted $\mathrm{OR}=2.49$, $95 \% \mathrm{CI}=1.89-3.27, \mathrm{p}=0.0001$ ). Out of total OSCC patients, $31 \%$ were belonging to lower class (Unadjusted $\mathrm{OR}=2.20$, $95 \% \mathrm{CI}=1.36-3.58, \mathrm{p}=0.001), 25.5 \%$ upper lower class (Unadjusted $\mathrm{OR}=1.93,95 \% \mathrm{CI}=1.18-3.16, \mathrm{p}=0.009$ ) and $22.7 \%$ lower middle class (Unadjusted $\mathrm{OR}=1.86$, $95 \% \mathrm{CI}=1.13-3.06, \mathrm{p}=0.01)$ of socio-economic status.

In OSCC patients, $5.7 \%$ patients were without any risk habits and $94.3 \%$ attributed by different types of risk habits. SLT chewers were the most prevalent $(34.6 \%)$ followed by combined habits of SLT chewing+TS (25.9 $\%)$ and Alcohol \pm SLT \pm TS $(25.3 \%)$. Risk habits pattern in control group, $36 \%$ subjects had both smoking and chewing habits of tobacco followed by only chewing habit of smokeless tobacco (32.2\%). The cases who did not have any bad habit were at lower risk of OSCC than SLT chewer (Unadjusted $\mathrm{OR}=0.48,95 \% \mathrm{CI}=0.28-0.82, \mathrm{p}=0.007$ ). The cases who had habit of both tobacco chewing and smoking (SLT+TS) were also at higher risk of OSCC than SLT users (Unadjusted OR=0.52,95\% CI=0.38-0.72, $\mathrm{p}=0.0001$ ). Higher duration of risk habit was observed to be a significant risk factor for OSCC (Unadjusted $\mathrm{OR}=1.42,95 \% \mathrm{CI}=1.36-1.49, \mathrm{p}=0.0001)$.

Figure 1 and Figure 2 represent the clinicopathological profile and affected oral anatomical sites in OSCC cases. 
Table 1. Demographic Characteristics and Risk Habits for OSCC Patients

\begin{tabular}{|c|c|c|c|c|c|c|c|}
\hline & & \multicolumn{2}{|c|}{ Cases $(n=471)$} & \multicolumn{2}{|c|}{ Controls $(n=556)$} & \multirow{2}{*}{$\begin{array}{l}\text { Unadjusted OR } \\
\qquad(95 \% \mathrm{CI})\end{array}$} & \multirow[t]{2}{*}{$\mathrm{p}$ value } \\
\hline & & No. & $\%$ & No. & $\%$ & & \\
\hline \multirow[t]{6}{*}{ Age in years } & $\leq 30$ & 48 & 10.2 & 81 & 14.6 & 1.00 (Ref.) & \\
\hline & $31-40$ & 120 & 25.5 & 153 & 27.5 & $1.32(0.86-2.03)$ & 0.20 \\
\hline & $41-50$ & 121 & 25.7 & 125 & 22.5 & $1.63(1.05-2.52)$ & $0.02 *$ \\
\hline & $51-60$ & 117 & 24.8 & 110 & 19.8 & $1.79(1.15-2.79)$ & $0.009 *$ \\
\hline & $61-70$ & 57 & 12.1 & 70 & 12.6 & $1.37(0.83-2.26)$ & 0.21 \\
\hline & $>70$ & 8 & 1.7 & 17 & 3.1 & $0.79(0.31-1.97)$ & 0.62 \\
\hline \multirow[t]{2}{*}{ Sex } & Male & 367 & 77.9 & 326 & 58.6 & $2.49(1.89-3.27)$ & $0.0001 *$ \\
\hline & Female & 104 & 22.1 & 230 & 41.4 & 1.00 (Ref.) & \\
\hline \multirow[t]{5}{*}{ Socio-economic status $\dagger$} & Upper class & 31 & 6.6 & 67 & 12.1 & 1.00 (Ref.) & \\
\hline & Upper middle class & 67 & 14.2 & 88 & 15.8 & $1.64(0.96-2.79)$ & 0.06 \\
\hline & Lower middle class & 107 & 22.7 & 124 & 22.3 & $1.86(1.13-3.06)$ & $0.01 *$ \\
\hline & Upper lower class & 120 & 25.5 & 134 & 24.1 & $1.93(1.18-3.16)$ & $0.009 *$ \\
\hline & Lower class & 146 & 31.0 & 143 & 25.7 & $2.20(1.36-3.58)$ & $0.001 *$ \\
\hline \multirow[t]{6}{*}{ Habit(s) } & SLT & 163 & 34.6 & 179 & 32.2 & 1.00 (Ref.) & \\
\hline & TS & 40 & 8.5 & 55 & 9.9 & $0.62(0.39-1.00)$ & 0.05 \\
\hline & SLT+TS & 122 & 25.9 & 200 & 36.0 & $0.52(0.38-0.72)$ & $0.0001 *$ \\
\hline & Alcohol \pm SLT \pm TS & 119 & 25.3 & 112 & 20.1 & $0.91(0.65-1.29)$ & 0.63 \\
\hline & No habit & 27 & 5.7 & 10 & 1.8 & $0.48(0.28-0.82)$ & $0.007 *$ \\
\hline & Duration of use in years & \multicolumn{2}{|c|}{$12.18 \pm 6.75$} & \multicolumn{2}{|c|}{$4.05 \pm 2.73$} & $1.42(1.36-1.49)$ & $0.0001 *$ \\
\hline
\end{tabular}

*Significant, †According to modified Kuppuswamy’s socio-economic scaleOR-Odds ratio, CI-Confidence interval, Ref: Reference category

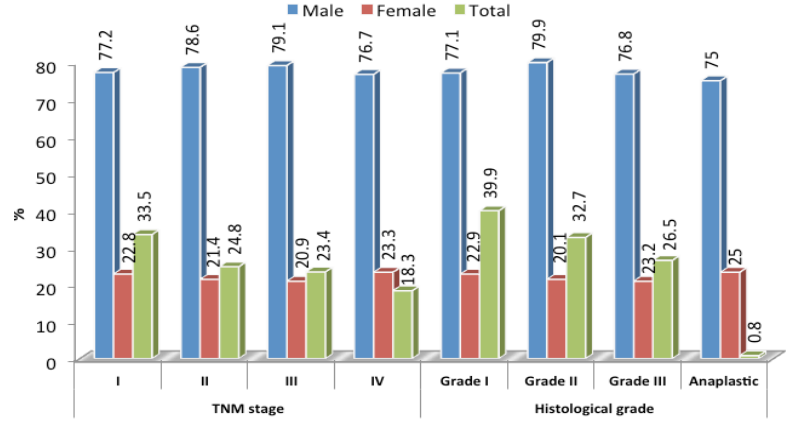

Figure 1. Distribution of OSCC Patients According to Clinical TNM Stage and Histology

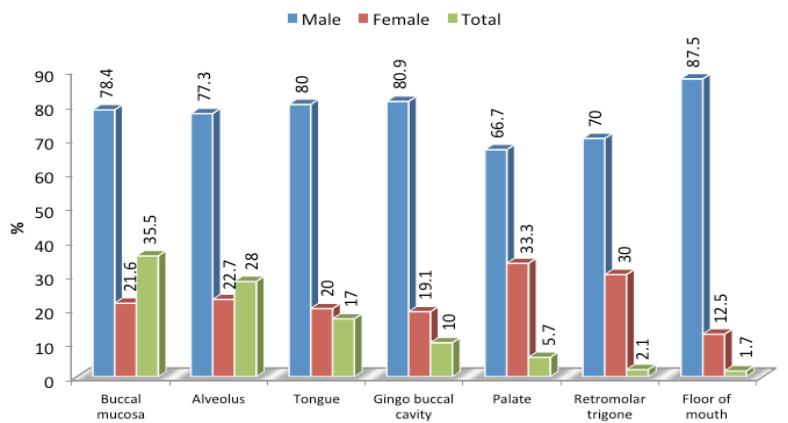

Figure 2. Distribution of OSCC Patients According to Affected Oral Cavity Sites

In clinical diagnosis, one third $(33.5 \%)$ of the patients were in TNM stage I and (24.8\%) were in TNM stage II. However, prevalence of advance stages (TNM stage III, IV) was $23.4 \%$ and $18.3 \%$ respectively. The percentage of different TNM staging was higher among male patients than females. Well differentiated OSCC (Grade I) found $39.9 \%$ followed by moderately, poorly differentiated carcinoma in histological grading. The most affected site of oral cavity was buccal mucosa $(35.5 \%)$ followed by alveolus (28\%), tongue (17\%) and gingo-buccal cavity $(10 \%)$. The percentage of other affected anatomic sites of oral cavity was less than $10 \%$. The percentage of affected anatomic sites of oral cavity was higher among
Table 2. Significant Risk Factors for OSCC PatientsResults of Multivariate Logistic Regression

\begin{tabular}{|c|c|c|c|c|}
\hline Adjus & usted OR 9 & $95 \%$ CI o & djusted OR & $\mathrm{p}$ value \\
\hline & & Lower & Upper & \\
\hline Age in years & & & & \\
\hline$\leq 30$ & 1.00 (Ref.) & & & \\
\hline $31-40$ & 0.74 & 0.40 & 1.34 & 0.32 \\
\hline $41-50$ & 0.52 & 0.28 & 0.96 & $0.03 *$ \\
\hline $51-60$ & 0.40 & 0.20 & 0.77 & $0.006^{*}$ \\
\hline $61-70$ & 0.39 & 0.19 & 0.81 & $0.01 *$ \\
\hline$>70$ & 0.35 & 0.09 & 1.25 & 0.10 \\
\hline Sex & & & & \\
\hline Male & 1.16 & 1.10 & 1.26 & $0.0001 *$ \\
\hline Female & 1.00 (Ref.) & & & \\
\hline Socio-economic status & & & & \\
\hline Upper class & 1.00 (Ref.) & & & \\
\hline Upper middle class & 2.10 & 0.87 & 5.06 & 0.09 \\
\hline Lower middle class & 3.50 & 1.53 & 7.99 & $0.003 *$ \\
\hline Upper lower class & 2.64 & 1.19 & 5.88 & $0.01 *$ \\
\hline Lower class & 2.16 & 0.98 & 4.79 & 0.06 \\
\hline Habit & & & & \\
\hline SLT & 1.00 (Ref.) & & & \\
\hline $\mathrm{TS}$ & 0.23 & 0.11 & 0.49 & $0.0001 *$ \\
\hline SLT+TS & 0.29 & 0.18 & 0.49 & $0.0001 *$ \\
\hline Alcohol \pm SLT \pm TS & 0.30 & 0.17 & 0.52 & $0.0001 *$ \\
\hline No habit & 0.23 & 0.11 & 0.45 & $0.0001 *$ \\
\hline Duration of use (years & s) 1.55 & 1.46 & 1.64 & $0.0001 *$ \\
\hline
\end{tabular}

*Significant; OR-Odds ratio; CI-Confidence interval; Ref: Reference category

males patients compared with females. It has been also observed, buccal mucosa was the commonest site of oral cavity among the patients with mixed type of risk habits (alcohol and tobacco). The majority of TNM stage I was higher in patients with habits of alcohol with or without combination of tobacco. The percentage of histological grading was varying with different type of risk habits.

The multivariate binary logistic regression analysis (Table 2) revealed that the patients of age 41-50, 51-60 and 61-70 years were at higher risk of OSCC than patients of age $\leq 30$ years. Males were at higher risk compared to females (Adjusted $\mathrm{OR}=1.16,95 \% \mathrm{CI}=1.10-1.26$, 


\section{Akhilesh Krishna et al}

$\mathrm{p}=0.0001$ ). The socio-economic status of the patients and different types of risk habits were also found to be significant risk factors for OSCC.

\section{Discussion}

The increasing incidence and mortality rates of OSCC are a major global health problem. Around more than 300,000 patients are annually estimated have to oral cancer worldwide (Funk et al., 2002; Rautava et al., 2007). However, OSCC shows a geographical variation with respect to the age, site, sex and habits of the population (Mehrotra et al., 2008). The present study is an unmatched case control study, so the number of control subjects was included more than case to increase the power of the study. The prevalence of OSCC patients was significantly higher in middle age groups (41-50 and 51-60 years) in our study. Some recent studies of India (Saraswathi et al., 2006; Kiran et al., 2012) have reported that majority of the OSCC patients were in the age group of 41 to 50 years and 40 to 61 years respectively. However, (Gangane et al., 2007) reported prevalence of oral malignancies mostly in the 50 to 59 years age group. About $17 \%$ of the younger patients are below 40 years of age (Halboub et al., 2011) or at least in the fourth decade of their life (Sherin et al., 2008). A study about Israeli Arab citizens (Avraham et al., 2012) reported, most of the diagnosed oral cancer cases were above 54 years of age $(53.7 \%)$. Considering ratio of OSCC according to gender, male are more affected $(77.9 \%)$ than female $(22.1 \%)$ with ratio $3.52: 1$, which was statistically significant $(\mathrm{p}=0.0001)$ and consistent with the study of (Agrawal and Rajderkar, 2012) who reported 3.57:1. Some other Indian studies (Mehrotra et al., 2008; Sharma et al., 2010) reported less male: female ratio in comparison to our finding. Another study by (Syeda et al., 2013), has enrolled to total 80 patients in their study. Out of 80 patients, maximum (38) were in the age group of 21-30 years and males females ratio 7.8:1. A study of Mexico City conducted by (Hernandez et al., 2013) revealed the prevalence of OSCC, $58.4 \%$ men, $41.6 \%$ women and male: female ratio $1.4: 1$. Some previous reports of Indian institutional studies and our result conclude that oral cancer occurred two to four times more commonly in male than female (Sharma et al., 2010; Aruna et al., 2011; Arvind and Vijayalakshmi, 2013). This might be due to geographical variations, high consumption of tobacco and alcohol by males, less epidemiological monitoring and clinical prevention or management, generally in India.

Low socioeconomic status contributes towards the risk of oral cancer (Krishna Rao et al., 2013). In this present study, most of the oral cancer patients were belonging to lower class and lower middle class that is significantly correlated to OSCC $(\mathrm{p}=0.001)$. Our findings are consistent with to another study by (Madani et al., 2010) who reported that risk of oral cancer is inversely proportional to increasing level of education and economical status. A recent work conducted in Delhi, India by Goyal et al. (2014) revealed that Majority cases were doing small business and either unemployed or labourer, more than half patients were from income less than Rs 10,000 (approximately US\$ 200) per month and $10 \%$ were from weaker section of society. In line to previous studies (Bhurgri, 2005; Ariyawardana et al., 2007; Warnakulasuriya, 2009; Hosseinpoor et al., 2012) from Asian countries have also reported that low socioeconomic status is a risk factor for oral cancer.

Our results showed that more number of cases $(39.9 \%)$ with well-differentiated OSCC (Grade I) in histopathological investigation. Other studies from India and across reported that most of OSCC cases diagnosed as moderately differentiated OSCC (Ayaz et al., 2011; Udeabor et al., 2012). The clinico-pathological factor that influence the treatment outcome and likelihood of recurrence are advanced $\mathrm{T}$ stage or stage III-IV disease at diagnosis, including local regional nodal involvement, positive resection margins or the resection margins being very close to the tumor and thickness of tumor $\geq 7 \mathrm{~mm}$ (Battoo et al., 2012; Hakeem et al., 2012). Present study showed the prevalence of clinical TNM stages of OSCC patients with advance stages (III, IV) $23.4 \%$ and $18.3 \%$ respectively. A similar study conducted in India by (Khandekar et al.,2006) reported, $47.5 \%$ advance cases in their study. Another study of Chennai, India by (Arvind and Vijayalakshmi, 2013) declared majority of the oral cavity cancers present in advanced stages (Stages III and IV). Recently (Goyal et al. 2014) revealed to the relationship between the oral hygiene, rural/urban area related patients and the stage of tumor. The clinico-pathological profile of OSCC patients, may suggest that the early diagnosis of oral cancer, based on pre-malignancies (leukoplakia or erythroplasia) and pre-cancer condition (dysplasia) detection is effective for adequate treatment and improved prognosis.

Asian countries have distinct cultural practices such as betel-quid chewing as well as varying patterns of use of tobacco and alcohol, which are important risk factors that cause oral cancer. Daily frequency and duration of alcohol and tobacco consumption have been observed in relationship to oral cancer development (Krishna Rao et al., 2013). In the study, prevalence of risk habit in OSCC was higher $(94.3 \%)$ in compare to other previous studies (Aruna et al., 2011; Patil et al., 2013). The high percentage of patients with risk habits is probably related to the early initiation of tobacco use especially in chewing form due to its easy availability, low cost and socio-cultural acceptance. The cases who had habits of SLT chewing+TS were at higher risk of OSCC than SLT users. Risk of OSCC for alcohol consumers was relatively much lower than tobacco chewers and smokers. A study by Lin et al. (2011) supported to our findings. Some previous studies reported that a great risk of oral cancer in consumers who chewing tobacco and kept in the mouth for different duration of time, depending on the personal habits (Muwonge et al., 2008; Madani et al., 2012). Contradictory results also have been obtained in other studies. They reported that alcohol has a synergistic effect with tobacco chewing and smoking (Gangane et al., 2007; Subapriya et al., 2007; Shenoi et al., 2012). Some reports by (Chung et al., 2005; Loyha et al., 2013; Maasland et al., 2014) found in their study that alcohol drinking was significantly associated with oral cancer. In India, there is significant variation across different states regarding both smoking as well as 
consuming smokeless tobacco. Tobacco chewing is more prevalent in the Central, Eastern and Northeastern states whereas smoking is relatively more common in Northern states (Gupta Bhawna; 2013). The multivariate analysis in the present study showed that age, sex, socio-economic status, risk habits with duration were significantly associated.

The oral anatomic sites involvements vary as well from region to another. It appears that the geographic location has no role with this rather than it is the oral habits popular in certain countries which vary from region to another (Omar EA, 2013). Our results showed that buccal mucosa was the most frequent affected site followed by alveolus, tongue, gingo buccal cavity and palate respectively. Some studies conducted in Pakistan, India, Taiwan reported cheek or buccal mucosa cancers exceed all other oral cancers (Bhurgri et al., 2003; Su et al., 2007; Sharma et al., 2010). Cancer of tongue is the leading site not only among oral cancers but also among head and neck cancers in India and across (Sanchez et al., 2008; Addala et al., 2012; Agarwal and Rajderkar, 2012; Bektas-Kayhan et al.2014). A study reported that highest risk of OSCC in the retromolar area followed by the floor of mouth and buccal mucosa for tobacco smokers while alcohol drinkers had risk significantly higher in floor of mouth than tongue (Jovanovich et al.,1993; Schmidt et al., 2004). Risk for tongue cancer increased with chewing tobacco for $\geq 15$ times in a day (Jayalekshmi et al., 2011). A study by (Sudha et al., 2014) depicted that long time khaini (SLT) use produces definite morphological and morphometric changes in the buccal mucosal cells, which may lead to cancer with prolonged exposure.

If we considered on OSCC patients without any risk habits in the study, it is urgent need to identify other features like poor oral hygiene, poor dental status, oncogenic viruses (human papilloma virus) and genetic predisposition, which may associate with the occurrence of oral cancer.

In conclusion, there are significant associations between OSCC and middle age group subjects predominantly male, lower socio-economic status and risk habits of tobacco chewing with smoking. Buccal mucosa was the most common site for primary tumor of oral cavity among mixed habit patients. The clinico-pathological profile of OSCC patients, majority of patients were presented in well-differentiate carcinoma. Prevalence of advance stages (TNM stage III, IV) was $23.4 \%$ and $18.3 \%$ respectively. Incidence of oral cancer is increasing in most Asian countries especially in India; hence, it is important to initiate the national level public awareness programs in various part of country to control and prevent oral cancer by screening for early diagnosis and support a tobacco free environment.

\section{Acknowledgements}

We would like to thank all the volunteers who participated in the study. We are also grateful to all the clinicians and the non clinical staff of Department of Oral and Maxillofacial Surgery, for their constant encouragement in this study.

\section{References}

Addala L, Pentapati CK, Reddy Thavanati PK, Anjaneyulu V, Sadhnani MD (2012). Risk factor profiles of head, neck cancer patients of Andhra Pradesh, India. Indian J Cancer, 49, 215-9

Agrawal KH, Rajderkar SS (2012). Clinicoepidemiological profile of oral cancer: A hospital based study. Indian $J$ Community Health, 24, 80-5.

Ariyawardana A, Sitheeque MA, Ranasinghe AW, et al (2007). Prevalence of oral cancer, pre-cancer, associated risk factors among tea estate workers in the central Sri Lanka. J Oral Pathol Med, 36, 581-7.

Aruna D, Prasad KVV, Shavi GR, et al (2011). Retrospective study on risk habits among oral cancer patients in Karnataka Cancer Therapy, Research Institute, Hubli, India. Asian Pac J Cancer Prev, 12, 1561-6.

Arvind K, Vijayalakshmi R (2013). Early stage oral tongue cancer among non-tobacco users -an increasing trend observed in a south indian patient population presenting at a single centre. Asian Pac J Cancer Prev, 14, 5061-5.

Avraham Z, Nasser N, Yuval V (2012) .Oral and pharyngeal cancer among the Arab population in Israel from 1970 to 2006. Asian Pac J Cancer Prev, 13, 585-9.

Ayaz B, Saleem K, Azim W, Shaikh A (2011).Aclinicopathological study of oral cancers. Biomedica, 27, 29-32.

Bagan J, Sarrion G, Jimenez Y (2010). Oral cancer: clinical features. Oral Oncol, 46, 414-7.

Battoo AJ, Hedne N, Ahmad SZ, et al (2012). Selective neck dissection is effective in N1/N2 nodal stage oral cavity squamous cell carcinoma. J Oral Maxillofac Surg, 71, 636-43.

Bektas-Kayhan K, Karagoz G, Kesimli MC, et al (2014). Carcinoma of the tongue: a case-control study on etiologic factors and dental trauma. Asian Pac J Cancer Prev, 15, 2225-9.

Bhurgri Y, Bhurgri A, Hussainy AS, et al (2003). Cancer of the oral cavity, pharynx in Karachi - Identification of potential risk factors. Asian Pac J Cancer Prev, 4, 125-30.

Bhurgri Y (2005). Cancer of the oral cavity - trends in Karachi south (1995-2002). Asian Pac J Cancer Prev, 6, 22-6.

Carvalho AL, Singh B, Spiro RH, Kowalski LP, Shah JP (2004). Cancer of the oral cavity: a comparison between institutions in a developing and a developed nation. Head Neck, 26,31-8.

Cogliano V, Straif K, Baan R, Grosse Y, et al (2004). Smokeless tobacco and tobacco-related nitrosamines. Lancet Oncol, 5,708 .

Conway DI, Petticrew M, Marlborough H, et al (2008). Socioeconomic inequalities and oral cancer risk: a systematic review and meta-analysis of case-control studies. Int $J$ Cancer, 122, 2811-9.

Chung CH, Yang YH, Wang TY, Shieh TY, Warnakulasuriya S (2005). Oral precancerous disorders associated with areca quid chewing, smoking, and alcohol drinking in southern Taiwan. J Oral Pathol Med, 34, 460-6.

Doshi Neena P, Shah Siddharth A, Patel Keyuri B, Jhabuawala Munira F (2011). Histological grading of oral cancer: A comparison of different systems and their relation to lymph node metastasis. Natl J Commun Med, 2, 136-42.

Funk GF, Karnell LH, Robinson RA, et al (2002). Presentation, treatment, and outcome of oral cavity cancer: a National Cancer Data Base report. Head Neck, 24, 165-80.

Gangane N, Chawla S, Anshu, Gupta SS, Sharma SM (2007). Reassessment of risk factors for oral cancer. Asian Pac J Cancer Prev, 8, 243-8.

Government of India (2009-10). Annual report, ministry of health and family welfare, New Delhi, India. 
Akhilesh Krishna et al

Goyal S, Tiwari VK, Nair KS, RajS (2014). Risk Factors and costs of oral cancer in a tertiary care hospital in Delhi. Asian Pac J Cancer Prev, 15, 1659-5.

Gupta Bhawna (2013). Burden of smoked and smokeless tobacco consumption in india results from the global adult tobacco survey India (GATS-India)- 2009-2010. Asian Pac J Cancer Prev, 14, 3323-9.

Hakeem AH, Pradhan SA, Tubachi J, Kannan R (2012). Outcome of per oral wide excision of T1-2 N0 localized squamous cell cancer of the buccal mucosa-analysis of 156 cases. Laryngoscope, 123, 177-80.

Halboub ES, Al-Anazi YM, Al-Mohaya MA (2011). Characterization of yemeni patients treated for oral, pharyngeal cancers in Saudi Arabia. Saudi Med J, 32, 1177-82.

Hernandez-Guerrero JC, Jacinto-Aleman LF, Jimenez-Farfan MD, et al (2013). Prevalence trends of oral squamous cell carcinoma. Mexico City's General Hospital experience. Med Oral Patol Oral Cir Bucal, 18, 306-11.

Hosseinpoor AR, Parker LA, Tursan d'Espaignet E, Chatterji S (2012). Socioeconomic inequality in smoking in low-income and middle-income countries: results from the world health survey. PLOS ONE, 7, 42843.

ICMR-Indian Council of Medical Research (2011). National cancer registry programme, Indian council of medical research, New Delhi.

Jayalekshmi PA, Gangadharan P, Akiba S, Koriyama C, Nair RR (2011). Oral cavity cancer risk in relation to tobacco chewing, bidi smoking among men in Karunagappally, Kerala, India: Karunagappally cohort study. Cancer Sci, 102, 460-7.

Jovanovic A, Schulten EA, Kostense PJ, Snow GB, van der Waal (1993). Tobacco and alcohol related to the anatomical site of oral squamous cell carcinoma. J Oral Pathol Med, 22, 459-62.

Khandekar SP, Bagdey PS, Tiwari RR (2006). Oral cancer and some epidemiological factors: a hospital based study. Indian J Community Med, 31, 157-9.

Kiran G, Shyam NDVN, Rao J, et al (2012). Demographics and histopathological patterns of oral squamous cell carcinoma at a tertiary level referral hospital in hyderabad, India: A 5-year retrospective study. J Orofac Res, 2, 198-201.

Krishna Rao SV, Mejia G, Roberts-Thomson K, Logan R (2013). Epidemiology of oral cancer in Asia in the past decade- an update (2000-2012). Asian Pac J Cancer Prev, 14, 5567-77.

Lin WJ, Jiang RS, Wu SH, Chen FJ, Liu SA (2011). Smoking, alcohol, betel quid, oral cancer: a prospective cohort study. J oncol, 2011, 525976.

Loyha K, Vatanasapt P, Promthet S, Parkin DM (2013). Risk factors for oral cancer in northeast Thailand. Asian Pac J Cancer Prev, 13, 5087-90.

Maasland DH, van den Brandt PA, Kremer B, Goldbohm RA, Schouten LJ (2014). Alcohol consumption, cigarette smoking and the risk of subtypes of head-neck cancer: results from the Netherlands cohort study. BMC Cancer, 14, 187.

Madani AH, Dikshit M, Bhaduri D, et al (2010). Relationship between selected socio-demographic factors, cancer of oral cavity - A case control study. Cancer Inform, 9, 163-8.

Madani AH, Dikshit M, Bhaduri D (2012). Risk for oral cancer associated to smoking, smokeless and oral dip products. Indian J Public Health, 56, 57-60.

Mathur A, Jain, M Shiva M, et al (2007). Tobacco habits and risk of oral cancer: a retrospective study in India. Iranian $J$ Blood and Cancer, 3, 111-6.

Mehrotra R, Singh MK, Pandya S, Singh M (2008). The use of an oral brush biopsy without computer-assisted anaylsis in the oral lesions: a study of 94 patients. Oral Surg Oral Med
Oral Pathol Oral Radiol Endod, 106, 246-53.

Ministry of Health and Family Welfare, Government of India. global adult tobacco survey report, India 2009-10.

Mishra D, Singh HP (2003). Kuppuswamy's scocioeconomic status scale-A revision. Indian J Pediatr, 70, 273-4.

Muwonge R, Ramadas K, Sankila R, et al (2008). Role of tobacco smoking, chewing, alcohol drinking in the risk of oral cancer in Trivandrum, India: a nested case-control design using incident cancer cases. Oral Oncol, 44, 446-54.

Omar EA (2013). The outline of prognosis and new advances in diagnosis of oral squamous cell carcinoma (OSCC): review of the literature. J Oral Oncol, 2013, 1-13

PB Patil, R Bathi, S Chaudhari (2013). Prevalence of oral mucosal lesions in dental patients with tobacco smoking, chewing, and mixed habits: A cross-sectional study in South India. J Family Community Med, 2, 130-5.

Petti S, Scully C (2005). Oral cancer: the association between nation-based alcohol-drinking profiles and oral cancer mortality. Oral Oncol, 41, 828-34.

Rautava J, Luukkaa M, Heikinheimo K, et al (2007). Squamous cell carcinomas arising from different types of oral epithelia differ in their tumor and patient characteristics and survival. Oral Oncol, 43, 911-9.

Sanchez GS, Juarez CT, Espinel Bermudez MC, et al (2008) . Hospital discharges for oral cancer in the Mexican Institute of Social Security, 1991-2000. Rev Med Inst Mex Seguro Soc, 46, 101-8.

Saraswathi TR, Ranganathan K, Shanmugam S, et al. (2006) . Prevalence of oral lesions in relation to habits: cross sectional study in South India. Indian J Dent Res, 17, 121-5.

Schmidt BL, Dierks EJ, Homer L, Potter B (2004). Tobacco smoking history and presentation of oral squamous cell carcinoma. J Oral Maxillofac Surg, 62, 1055-8.

Sharma P, Saxena S, Aggarwal P (2010). Trends in the epidemiology of oral squamous cell carcinoma in Western UP: An institutional study. Indian J Dent Res, 21, 316-9.

Shenoi R, Devrukhkar V, Chaudhuri, Sharma BK, et al (2012). Demographic and clinical profile of oral squamous cell carcinoma patients: A retrospective study. Indian J Cancer, 49, 21-6.

Sherin N, Simi T, Shameena PM, Sudha S (2008). Changing trends in oral cancer. India J Cancer, 45, 93-6.

Subapriya R, Thangavelu A, Mathavan B, Ramachandran CR, Nagini S (2007). Assessment of risk factors for oral squamous cell carcinoma in Chidambaram, Southern India: a case-control study. Eur J Cancer Prev, 16, 251-6.

Sudha S, Saranya R S (2014). Cytomorphological changes in buccal epithelial cells of khaini chewers in different age groups. Asian J Biomed Pharmaceut Sci. 4, 43-7.

Syeda AA, Vini A, Syed Z, et al (2013). Correlation of habits and clinical findings with histopathological diagnosis in oral submucosal fibrosis patients. Asian Pac J Cancer Prev, 14, 7075-80.

Su CC, Yang HF, Huang SJ, Lian leB (2007). Distinctive features of oral cancer in Changhua county: high incidence, buccal mucosa preponderance, and a close relation to betel quid chewing habit. J Formos Med Assoc, 106, 225-33.

Udeabor SE, Rana M, Wegener G, Gellrich NC, Eckardt A. M (2012). Squamous cell carcinoma of the oral cavity and the oropharynx in patients less than 40 years of age: a 20 -year analysis. Head Neck Oncol, 28, 2-7.

Warnakulasuriya S, Sutherland G, Scully C (2005). Tobacco, oral cancer and treatment of dependence. Oral Oncol, 41, 244-60.

Warnakulasuriya S (2009). Causes of oral cancer-an appraisal of controversies. Br Dent J, 207, 471-5.

WHO (2004). The world health report 2004: changing history Geneva. http://www.who.int/whr/2004/en/report04_en.pdf 